\title{
Cognition and Emotion in Extreme Political Action: Individual Differences and Dynamic Interactions
}

\author{
Leor Zmigrod $^{1,2,3}$ \& Amit Goldenberg ${ }^{4}$
}

Affiliations: $\quad{ }^{1}$ Department of Psychology, University of Cambridge, Cambridge, UK

\author{
${ }^{2}$ Behavioural and Clinical Neuroscience Institute, University of Cambridge, \\ Cambridge, UK \\ ${ }^{3}$ Churchill College, University of Cambridge, Cambridge, UK \\ ${ }^{4}$ Harvard Business School, Harvard University, Cambridge, MA, USA
}

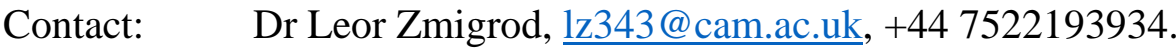

Paper accepted and in press at Current Directions in Psychological Science. Can be temporarily cited as:

Zmigrod, L., \& Goldenberg, A. (2020). Cognition and Emotion in Extreme Political Action: Individual Differences and Dynamic Interactions. Current Directions in Psychological Science. https://doi.org/10.31234/osf.io/w3hj6 


\begin{abstract}
Who is most likely to join and engage in extreme political action? While traditional theories have focused on situational factors or group identity attributes, an emerging science illustrates that tendencies for extreme political action may also be rooted in individuals' idiosyncratic cognitive and affective dispositions. This paper synthesizes cutting-edge evidence demonstrating that an individual's cognitive and affective architecture shape their willingness to support ideological violence. From a cognitive perspective, traits such as cognitive rigidity, slower perceptual strategies, and poorer executive functions are linked to heightened endorsement for ideological violence. From an emotional standpoint, characteristics associated with emotional reactivity and impaired emotional regulation, such as sensation-seeking and impulsivity, can facilitate readiness for extreme political action. The review hones in on the roles of cognitive rigidity and sensation-seeking as traits heightening proclivities for extreme pro-group behavior, and recommends that future research should aim to assess cognition-emotion interactions to reveal different sub-profiles of political actors. A theoretical framework focused on cognitive and affective information-processing traits - and their interactions - opens up tractable empirical questions and a future research agenda. Identifying subsets of ideologues is an endeavor with potential to inform the design of evidence-based interventions aimed at reducing ideological extremism and fostering social understanding.
\end{abstract}

Extreme political action; ideology; cognition; emotion; political psychology; cognitionemotion interactions 


\section{Psychological Theories of Extreme Political Action}

In his brilliant 1951 book The True Believer, the thinker Eric Hoffer pondered why some people are more likely than others to engage in extreme ideological action - action that promotes violence against others in the name of a group or cause. Who is most likely to participate in the behaviors of extreme or fanatical ideologies? Hoffer theorized the root of radicalization lied in low self-esteem and frustration, in the desire to discard and forget oneself by immersing in a larger collective. Since then, over the last 70 years, research has moved away from the self-esteem hypothesis towards a more systematic study of how contexts and motivations shape individuals' willingness to participate in extreme political action. Prominent psychological theories frequently concentrate on identity and situational factors such as age, gender, socioeconomic circumstance, level of hardship, or the individual's sense of efficacy, empowerment, or identification with the group (Drury \& Reicher, 2005; Van Zomeren et al., 2008). Other theoretical accounts center on high-level motivational factors, specifically on how general human motivations to experience coherence, certainty, and connectedness, can drive individuals to join ideological groups and movements (Jost, Ledgerwood, \& Hardin, 2008; Douglas, Sutton, \& Cichocka, 2017). These theoretical perspectives have generated important insights about how social, economic, and existential conditions can amplify an individual's proneness to engage in extreme ideological action.

Nonetheless, these lines of research have sometimes overlooked the contribution of deeply-rooted generalized individual differences that are internally embedded in the individual's brain architecture, and not necessarily shared by all. These traits reflect the individual's way of processing and evaluating information in general, in their everyday interactions with the world, with any kind of stimuli across a variety of domains, rather than in the specific context of politics. These individual-level attributes are often unconscious and 
grounded in biological idiosyncrasies in how brains operate, leading to slight - but significant - variations in how different individuals perceive stimuli and make decisions (Miyake \& Friedman, 2012). Given the abundance of socio-political opinions and decisions humans form throughout their lifetime, it is thus fruitful to ask whether such implicit informationprocessing tendencies affect individuals' propensities for political action.

Here we will synthesize recent research suggesting that susceptibility to extreme political action is sculpted by an individual's biologically-rooted cognitive and affective architecture, not only by their situational and motivational characteristics. Cognition refers to information processing of neutral stimuli in the service of decision-making (e.g. how individuals process visual shapes and judge them according to task instructions) whereas emotion is engaged in processing emotionally-valenced or emotionally-provocative stimuli (e.g. how individuals evaluate fearful or disgusted faces). Although most psychological processes are infused with both cognitive and affective components, for example memory or learning from rewards and punishments, we make this stimulus-oriented distinction for the sake of simplicity and clarity, in accordance with cognitive psychology conventions (Zajonc, 1984). We will further argue that future research should address nuanced cognition-emotion interactions and that this can shed light on the origins of extreme ideological action and the multitude of heterogeneous actors that it attracts.

\section{Cognitive Underpinnings of Extreme Political Action}

Individual differences in proclivities for extreme political action have been shown to relate to implicit cognitive characteristics across multiple psychological domains. One information-processing style that has been illustrated as a core correlate of ideological thought is cognitive rigidity. Cognitive rigidity is marked by a difficulty to adapt behavior in response to changing environments, task demands, and reward contingencies. Cognitively 
inflexible individuals perform more poorly on tasks such as the Wisconsin Card Sorting Test (WCST) or the Alternative Uses Test which require participants to process and respond to visual or linguistic stimuli in an adaptable manner. For instance, in the WCST, participants are instructed to sort cards according to their shape, color, or other visual feature. The cardsorting rule then changes, and individuals who are cognitively flexible are able to change their behavior in accordance with the new rule, while rigid individuals struggle to adapt to the new task demands. Individuals who exhibit cognitive inflexibility in these objective neuropsychological tasks also possess more ideological and dogmatic worldviews (Zmigrod, 2020) in the realm of nationalism (Zmigrod, Rentfrow, \& Robbins, 2018), politics (Zmigrod, Rentfrow, \& Robbins, 2020; Van Hiel et al., 2016), religiosity (Zmigrod et al., 2019a), and evidence receptivity (Zmigrod et al., 2019b). Importantly, in line with horseshoe theories of political extremism, cognitive rigidity characterizes individuals on the extreme right and extreme left of the political spectrum (Zmigrod, Rentfrow, \& Robbins, 2020; Figure 1A), showing that the extremity of the ideology may matter more than its content or mission.

In the context of extreme political action, cognitive rigidity predicted a greater willingness to endorse violence to protect an ideological group or cause (Zmigrod et al., 2019c; Figure 1B), as well as a readiness to sacrifice one's life to save other fellow ingroup members. Notably, individuals who had greater conviction or confidence in their decision to self-sacrifice for the sake of a broader ideological group tended to be more cognitively inflexible across multiple tasks. Individuals' implicit dispositions in the domain of cognitive rigidity and flexibility can therefore play a significant role in political judgements and behaviors - acting as individual-level factors that augment or reduce the likelihood of engaging in political action. 

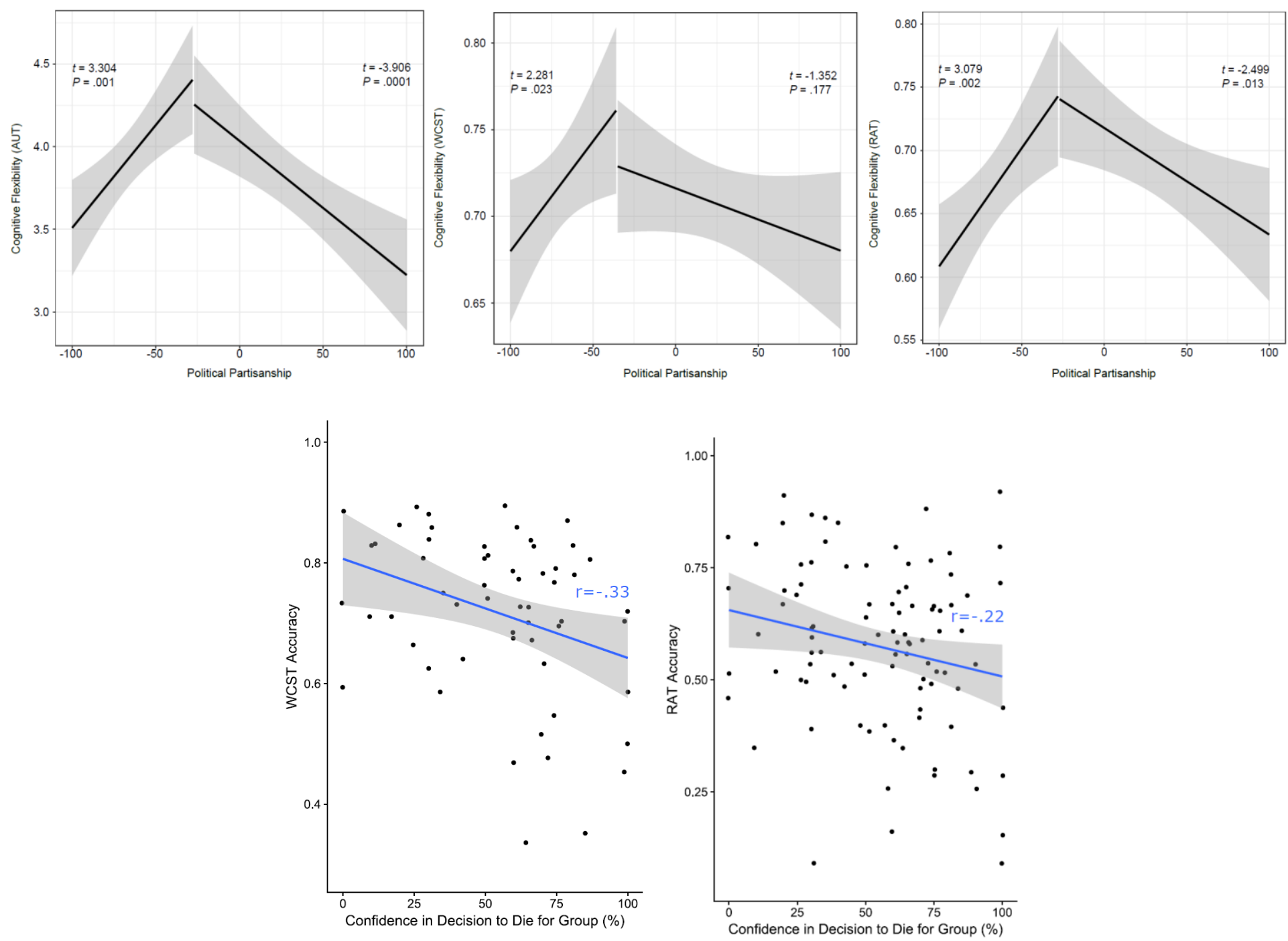

Figure 1. (A) Inverted $U$-shaped curves in cognitive flexibility across three independent tasks, whereby individuals strongly fused either to the Democratic party (negative partisanship values) or Republican party (positive values) were less cognitively flexible than moderates on the Alternative Uses Test (AUT), Wisconsin Card Sorting Test (WCST), and Remote Associates Test (RAT). Reproduced with permission from Zmigrod, Rentfrow, \& Robbins (2020). (B) Cognitively rigid participants were more likely to have strong conviction that they would be willing to die in order to save members of their ideological ingroup. Reproduced with permission from Zmigrod, Rentfrow, \& Robbins (2019).

Rigidity may also manifest in the context of metacognition, that is, the awareness of one's cognitive capacities and processes. Difficulties in metacognition may drive individuals to stick more rigidly and dogmatically to ideological scripts or extreme identities. In a metacognition paradigm by Rollwage and colleagues (2018), participants were asked to make a perceptual decision about which of two squares has a greater density of dots, and then to 
indicate their confidence in their decision. Individuals who perform well on this metacognitive task are able to discriminate between their accurate and inaccurate perceptual decisions, while metacognitively impaired individuals cannot track their own performance well. Rollwage and colleagues (2018) found that ideologically extreme individuals tended to perform more poorly on a metacognitive task relative to moderates. This suggests that extremism may be tied to a difficulty to regulate one's knowledge and mental processes, a finding corroborated by several research groups (Rollwage et al., 2019; Kleitman et al., 2019; Sinclair et al., 2019).

In addition to cognitive rigidity and impaired metacognitive awareness, tendencies to adopt extreme pro-group attitudes may also be rooted in more general difficulties with complex cognitive processing involved in planning and working memory. In a data-driven study, Zmigrod and colleagues (2020) tested over three dozen classic neuropsychological tasks from the cognitive psychology cannon, and investigated the relationships between performance on these tasks with extreme pro-group attitudes. Psychological measures were administered two years prior to the ideological questionnaires, lending a temporal dimension to the analysis: psychological traits preceded or were contemporaneous with ideological worldviews. The study conducted simultaneous regressions to predict individuals' endorsement of extreme pro-group actions from a range of psychological behavioural tasks (Figure 2A) and personality surveys (Figure 2B). Figure 2 depicts the standard estimates (beta) of these simultaneous regression analyses.

The tasks administered include classic executive functioning paradigms implicated in planning and working memory (summarized by "strategic information processing"), such as the Tower of London task where participants must mentally preplan and problem-solve how they would move a series of colored disks stacked on top of each other from an initial state to a new state presented in a figure to the participants. Another example is the Keep Track task, 
which is used to quantify how many items an individual can hold in working memory at the same time. As shown in Figure 2A, proclivities for extreme pro-group action were significantly associated with poorer performance these strategic information processing tasks. Difficulties in these strategic information processing domains may therefore subconsciously push individuals towards extreme doctrines that prescribe action and provide clear explanations of the world, and so make less stringent demands on working memory.

Additionally, the study administered perceptual decision-making tasks (called twoalternative forced choice tasks, 2AFC), in which participants were asked to make a series of fast and accurate choices amongst two visual stimuli. Classic tasks used include a LocalGlobal Task, in which participants are presented with a "global" figure (e.g. an "H") which is composed of smaller "local" figures (e.g. "O"s). On some trials, participants need to indicate the "global" shape and in other trials they are asked to indicate the "local" shape depending on instructions, and are asked to do this as quickly and precisely as possible. Computational modelling can then be applied on these kinds of 2AFC tasks in order to extract individuals' tendencies towards slow-and-accurate or fast-and-imprecise strategies - a cognitive variable called caution. It is also possible to estimate how much time it took participants to process the perceptual stimuli (called perceptual processing time) and how quickly they accumulated relevant evidence before making a decision (speed of evidence accumulation). Using methods to analyze multiple tasks at once, individuals' performance on dozens of these cognitive tasks were united into robust individual differences variables that represented these cognitive processes. The findings reveal that individuals who possessed extreme pro-group attitudes exhibited slower processing of perceptual (visual) stimuli and greater caution in perceptual decision-making tasks that require participants to make a rapid and accurate choice between two visual stimuli (Figure 2A). Hence, individual differences in low-level perceptual tendencies are linked to endorsement of ideological violence: one's willingness to engage in 
extreme political action may thus be linked to how one processes evidence from the decision environment in general - even in basic perceptual contexts.
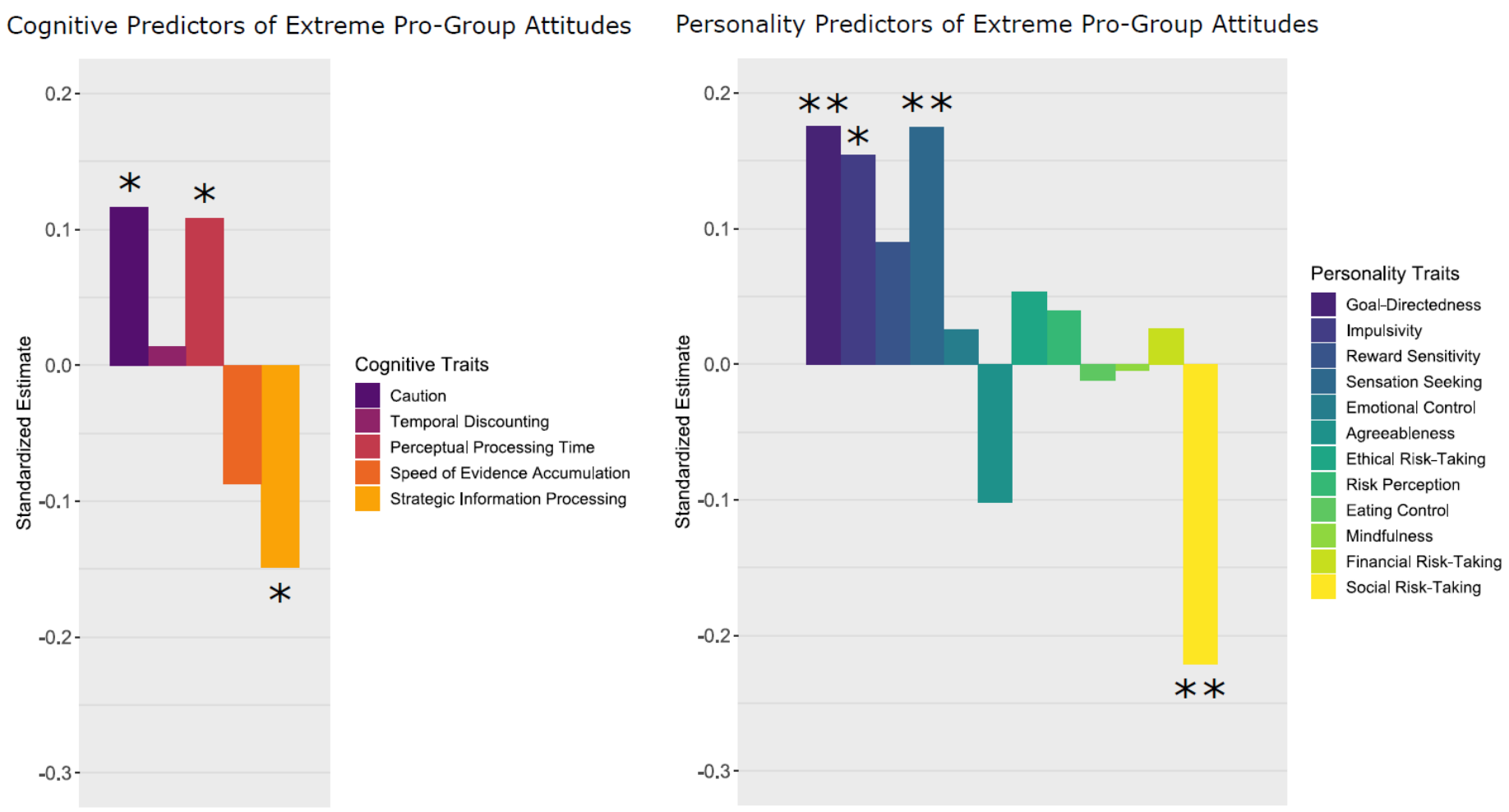

Figure 2. Regressions predicting individual differences in extreme pro-group attitudes, using $(A)$ cognitive tasks and $(B)$ personality surveys as the predictors. The y-axis indicates the standardized estimate (beta) from simultaneous regression analyses with extreme pro-group attitudes as the outcome variable. Significance levels indicate whether variable was a significant predictor of extreme pro-group attitudes, including support for ideological violence against outgroups to protect the ingroup. ${ }^{*} p<.05, * * p<.01$. Adapted from Zmigrod and colleagues (2020).

\section{Emotional Roots of Extreme Political Action}

Perhaps one of the most obvious aspects of any political action is that it highly emotional (Goodwin, Jasper, \& Polletta, 2000; Valentino et al., 2011). Yet despite our augmented understanding of how emotions are transmitted and regulated in intergroup and political contexts (Goldenberg, Halperin, van Zomeren, \& Gross, 2016), we know remarkably little about how general individual-level affective dispositions may be associated with 
political action, especially in the context of support for extreme pro-group actions such as violence.

It can be productive to evaluate the emotional roots of extreme political action in terms of two focal components in the affective process: emotional reactivity and emotion regulation. Emotional reactivity refers to the length and the extent to which an individual experiences emotions in response to a stimulus before returning to baseline level of arousal (Nock et al., 2008). Given the stability of emotional reactivity across situations (Silvers et al., 2012), it is likely that emotional reactivity, particularly to negative emotions, predicts responses to political situations and therefore political action.

In the data-driven study by Zmigrod and colleagues (2020) described above, several personality traits associated with emotional reactivity were implicated in extreme pro-group attitudes. Two traits that were particularly important were impulsivity and sensation-seeking and impulsivity (see Figure 2B). Impulsivity relates to emotional reactivity that leads to actions that are poorly conceived, prematurely expressed, and are unduly risky, or inappropriate to the situation (Evenden, 1999). Heightened impulsivity was associated with support for ideological violence (Figure 2B), suggesting that general impairments in inhibitory control in response to rewards and punishments may amplify an individual's likelihood of engaging in extreme political action. Sensation-seeking is the need to maintain reactivity by seeking intense and complex emotional sensations, coupled with the willingness to take risks in order to attain such experiences. The findings indicate that individuals with extreme pro-group attitudes tend to self-report as high sensation-seekers. An affective disposition that seeks high levels of stimulation in general thus appears to facilitate seeking extreme ideological experiences in particular. The emotional profile of the extreme political actor may therefore be characterized by a heightened craving for intense emotional 
experiences along with impulsivity in contexts that require a level of emotional control and regulation.

A positive association between emotional reactivity and tendencies towards extreme political behavior has also been corroborated by studies that use psychophysiological techniques to measure emotional reactivity. Through clever experimental design, Swann and colleagues (2010) found that elevating autonomic arousal led to heightened endorsement of extreme pro-group actions, especially in people who highly fused with the group beforehand. Furthermore, a meta-analysis by Lorber (2004) identified associations between psychophysiological reactivity and interpersonal aggression $(d=.10)$ and anti-social conduct problems $(d=.20)$, both of which could reasonably be positively associated with extreme ideological actions. The relationship between reactivity and extreme political action may also be nonlinear, especially because individuals characterized by very high reactivity also display avoidance from emotionally-intense situations (Nock et al., 2008).

A second key affective process relevant to the political realm is emotion regulation, the activation of a goal so as to influence the emotion trajectory (Gross, Sheppes, \& Urry, 2011). One useful strategy for emotion regulation is cognitive reappraisal. Cognitive reappraisal is the ability to modify how one thinks of an emotion eliciting situation in a way that leads to changes in one's emotional trajectory (Uesberg et al., 2019). For example, in response to an anger-inducing speech by a controversial political leader, an individual may regulate their emotions by assuring themselves of the historical significance of this leader. Indeed, teaching Israelis to use reappraisal to reduce negative emotions in the context of the Israeli-Palestinian conflict has been associated with a reduction in negative attitudes by Jewish-Israeli participants toward Palestinians as well increased willingness to make concessions for peace (Halperin, Porat, Tamir, \& Gross, 2013). 
While there has been increasing interest in regulation of emotions driven by grouprelated political situations (for a review see: Goldenberg, Halperin, van Zomeren, \& Gross, 2016), the investigation of how individual-level tendencies for emotional regulation sculpt inclinations for political action is in its infancy. Research by Ford, Feinberg and colleagues (2018) illustrates that Clinton voters in the 2016 US Election who used reappraisal to manage their emotions in response to Trump's election were less likely to partake in political action. Further longitudinal investigation of the association between reappraisal and political action suggests that using reappraisal may thus be a double-edged sword (Feinberg et al., 2020; Ford \& Feinberg, 2020): while it helps the individual to cope with negative emotions related to politics, it can hinder the motivation to change the status quo through action. Investigating how emotion regulation strategies impact predispositions in relation to normative and extreme political action is thus a worthwhile future research avenue.

\section{Future Directions: Cognition-Emotion Interactions}

Given that cognition and emotion are psychologically and neurally intertwined, and that ideological discourse is often composed of both rational ("cold") argumentation and passionate ("hot") persuasion, it is important to consider the functional interactions between cognitive and affective dispositions in order to elucidate the psychological underpinnings of political action (see Figure 3A). Methodologically and analytically it can be challenging to hypothesize and examine cognition-emotion interactions, and so we will outline an exemplar of how this can be achieved theoretically. 
Cognitive

Dispositions
Affective

Dispositions

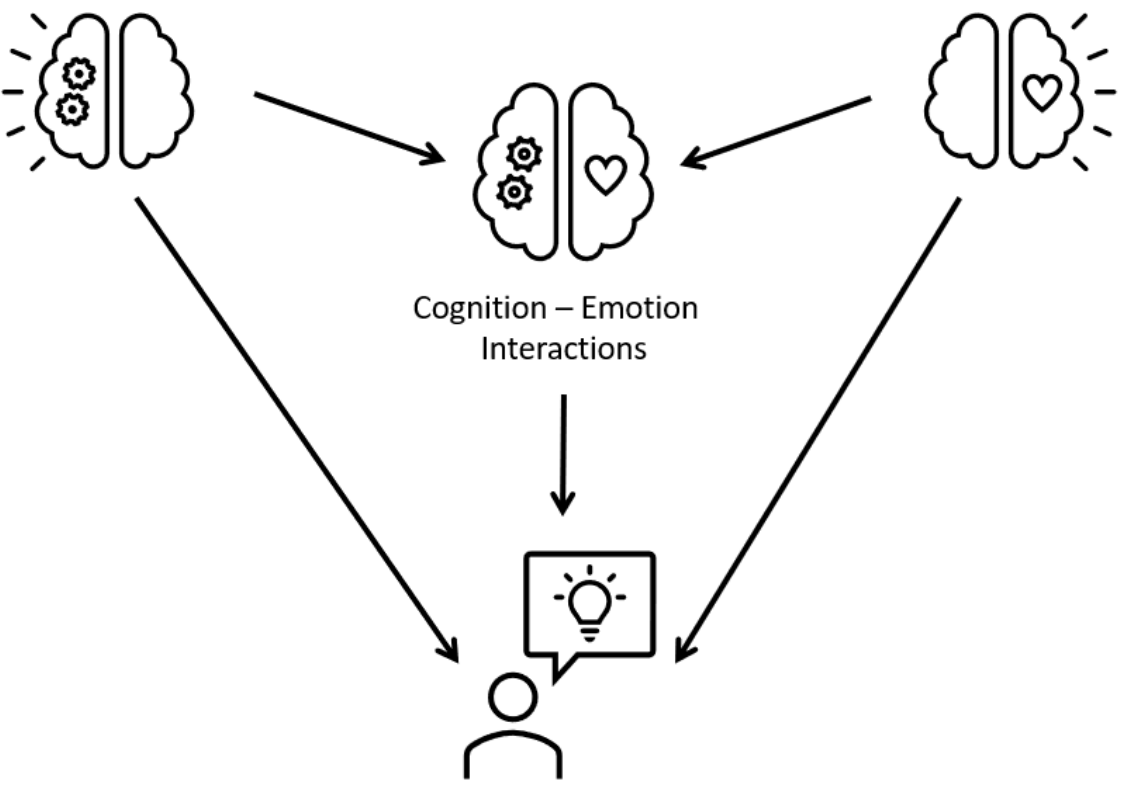

A

Tendencies toward Extreme Political Action

\begin{tabular}{|c|c|c|c|}
\hline & \multicolumn{2}{|c|}{ Cognitive Rigidity } \\
\hline & & Low & High \\
\hline \multirow{2}{*}{ 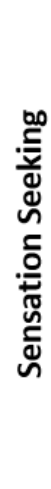 } & $\frac{\sqrt{00}}{\underline{\underline{00}}}$ & $\begin{array}{l}\text { Moderate } \\
\text { likelihood of } \\
\text { engaging in } \\
\text { extreme political } \\
\text { action, driven by } \\
\text { affective-relational } \\
\text { ("hot") motivations }\end{array}$ & $\begin{array}{l}\text { High likelihood of } \\
\text { engaging in } \\
\text { extreme political } \\
\text { action, driven by } \\
\text { both "hot" and } \\
\text { "cold" psychological } \\
\text { processes }\end{array}$ \\
\hline & కై & $\begin{array}{l}\text { Low likelihood of } \\
\text { engaging in } \\
\text { extreme political } \\
\text { action }\end{array}$ & $\begin{array}{l}\text { Moderate } \\
\text { likelihood of } \\
\text { engaging in } \\
\text { extreme political } \\
\text { action, driven by } \\
\text { doctrinal ("cold") } \\
\text { motivations }\end{array}$ \\
\hline
\end{tabular}
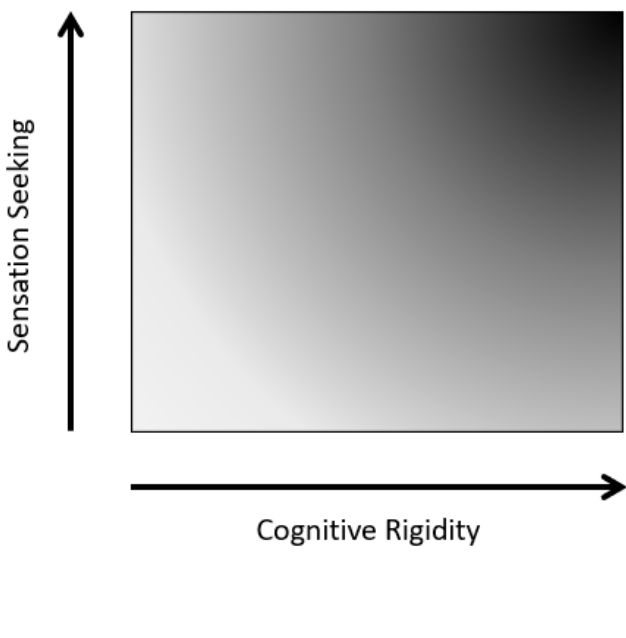

Support for Ideological Violence

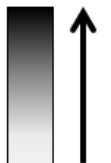

B

Figure 3. (A) A conceptual model showing consideration of cognitive traits, affective traits, and their interactions in shaping extreme ideological attitudes and actions. (B) A theoretical example of the interaction between cognitive rigidity and sensation-seeking in shaping likelihood of engaging in extreme ideological action. This interaction assumes that the interaction operates in a multiplicative fashion, such that high cognitive rigidity and high sensation seeking produce the most ideologically extreme psychological profile.

As outlined above, support for ideologically-motivated violence is amplified by cognitive rigidity as well as sensation-seeking, to take two examples. It is plausible and likely 
that these traits interact to shape tendencies for political action. If a person is characterized by both high cognitive rigidity and high sensation-seeking, they will be rigid in how they interpret their (political) environment and susceptible to emotional triggers when negative events befall their ideological group. They may therefore be highly likely to immerse themselves in collective ideologies and demonstrate a willingness to support violence for the sake of the cause or group (see Figure 3B). In contrast, if a person possesses low cognitive rigidity and low sensation-seeking, they will be able to flexibly evaluate events and arguments in their (political) environment and will be emotionally resilient to emotional contagion effects by others in their surroundings or to the allure of sensation-fulfilling extreme collective acts. Consequently, they will have a low likelihood of engaging in extreme political action or being swept up in emotionally-charged or polarizing social movements, all other situational and group-level factors being equal.

Perhaps the most interesting cases in interaction models can be found when an individual is low on one trait and high on the other. In the case of an individual who is highly cognitively rigid but low in sensation seeking, we can posit that they will have a moderate likelihood of participating in extreme ideological action, perhaps motivated more clearly by dogmatic doctrinal issues than by a desire to seek emotionally-intense experiences. In the case of an individual who is cognitively flexible but high in sensation-seeking, it may be reasoned that they will also have a moderate likelihood of engaging in ideologicallymotivated behavior, but they will be driven by a strong craving for emotionally-intense social experiences.

Examining interaction models may therefore reveal different sub-profiles of political actors, such as those who are characterized by affective-relational motivations versus those who have dogmatic tendencies (Zmigrod, 2020b). If we focused purely on one trait, we would miss the nuance between different sub-profiles and predictor models. Interaction 
models can also reveal various types of trait-by-trait interactions, such as those that are multiplicative (i.e. traits compound each other's effect) or compensatory (traits substitute each other's effect). This interactionist approach can allow us to conduct more sophisticated risk assessments of vulnerable individuals by elucidating the gradients of risk along which an individual may be positioned, depending on the number and type of relevant traits the individual possesses. In addition to assessment, this approach better positions practitioners to tailor interventions that focus on the specific psychological domain on which the individual may be impaired. For example, personalizing interventions that improve emotion regulation strategies or enhance cognitive flexibility and other executive functions, or target a customized cocktail of these psychological processes. Knowledge of trait-by-trait interactions can facilitate better estimation of the efficacy of such targeted interventions.

\section{Conclusions}

Not all individuals are equally likely to engage in extreme political action, and not all those who do have the same psychological profile. A burgeoning line of research suggests that certain cognitive and affective traits may enhance one's support for extreme ideological behavior. From a cognitive perspective, traits such as cognitive rigidity, impaired metacognition, slower perceptual strategies, and poorer executive functions have been correlated with heightened endorsement for ideological violence. From an emotional standpoint, characteristics associated with emotional reactivity and impaired emotional regulation, such as sensation-seeking and impulsivity, can facilitate readiness for extreme political action. Consequently, situational and motivational characteristics may only be part of the story when we consider who is most likely to commit extreme pro-group behavior; individual differences in biologically-rooted mental processes may be key - but often elusive - predictors (Jost, Nam, Amodio, \& Van Bavel, 2014). A new line of research using neuropsychological brain damage to examine the causal links between biology, cognition, and ideology has shown that 
amygdala and prefrontal cortex damage are associated with ideological conservatism (Nam, Jost, Meager, \& Van Bavel, 2021), indicating that neural processes directly bear on ideological tendencies. Further elucidation of causality is currently under investigation with longitudinal designs, biologically-sensitive paradigms, and computational modelling (Zmigrod \& Tsakiris, in press), as well as theoretical perspectives that consider the bidirectional links between individual differences in cognitive and ideological domains (Zmigrod, 2020).

Psychological science has now matured to enable nuanced analyses of interaction effects between cognition and emotion, allowing us to unearth different psychological subprofiles of different political actors. This approach can illuminate who is most vulnerable and who is most resilient to ideological extremism - and why. It also elucidates hidden similarities and discrepancies in the minds of those willing to take extreme measures to support their ideological doctrines, regardless of the ideology's mission. This can buttress depolarization efforts by highlighting common vulnerability factors that can motivate extremist behavior in diverse ideological settings and by demonstrating that the implicated psychological domains - such as cognitive flexibility, metacognition, emotion regulation are malleable in themselves and amenable to training and education. This research therefore has the potential to allow societies and individuals to harness the power of human cognition and the malleability of human emotion to find common ground and civil compromise. 


\section{References}

Douglas, K. M., Sutton, R. M., \& Cichocka, A. (2017). The psychology of conspiracy theories. Current directions in psychological science, 26(6), 538-542.

Drury, J., \& Reicher, S. (2005). Explaining enduring empowerment: A comparative study of collective action and psychological outcomes. European journal of social psychology, 35(1), 35-58.

Evenden, J. L. (1999). Varieties of impulsivity. Psychopharmacology, 146(4), 348-361.

Feinberg, M., Ford, B. Q., Thai, S., Gatchpazian, A., \& Lassetter, B. (2020, September 19). The Political is Personal: Daily Politics as a Chronic Stressor. https://doi.org/10.31234/osf.io/hdz97

Ford, B. Q., \& Feinberg, M. (2020). Coping with Politics: The Benefits and Costs of Emotion Regulation. Current Opinion in Behavioral Sciences, 34, 123-128. https://doi.org/10.1016/j.cobeha.2020.02.014

Ford, B. Q., Feinberg, M., Lam, P., Mauss, I. B., \& John, O. P. (2018). Using reappraisal to regulate negative emotion after the 2016 U.S. presidential election: Does emotion regulation Trump political action? Journal of Personality and Social Psychology, 117(5), 998-1015. https://doi.org/10.1037/pspp0000200

Goldenberg, A., Halperin, E., van Zomeren, M., \& Gross, J. J. (2016). The process model of group-based emotion: Integrating intergroup emotion and emotion regulation perspectives. Personality and Social Psychology Review, 20(2), 118-141. https://doi.org/10.1177/1088868315581263

Goodwin, J., Jasper, J. M., \& Polletta, F. (2000). The Return of The Repressed: The Fall and Rise of Emotions in Social Movement Theory. Mobilization; An International Quarterly, 
5(1), 66-83. Retrieved from

http://mobilizationjournal.org/doi/pdf/10.17813/maiq.5.1.74u39102m107g748

Gross, J. J., Sheppes, G., \& Urry, H. L. (2011). Emotion generation and emotion regulation: A distinction we should make (carefully). Cognition and Emotion, 25(5), 765781

Halperin, E., Porat, R., Tamir, M., \& Gross, J. J. (2013). Can emotion regulation change political attitudes in intractable conflicts? From the laboratory to the field. Psychological Science, 24(1), 106-111. https://doi.org/10.1177/0956797612452572

Jost, J. T., Ledgerwood, A., \& Hardin, C. D. (2008). Shared reality, system justification, and the relational basis of ideological beliefs. Social and Personality Psychology Compass, 2(1), 171-186.

Jost, J. T., Nam, H. H., Amodio, D. M., \& Van Bavel, J. J. (2014). Political neuroscience: The beginning of a beautiful friendship. Political Psychology, 35, 3-42.

Kleitman, S., Hui, J. S. W., \& Jiang, Y. (2019). Confidence to spare: individual differences in cognitive and metacognitive arrogance and competence. Metacognition and Learning, 14(3), 479-508.

Lorber, M. F. (2004). Psychophysiology of aggression, psychopathy, and conduct problems: A meta-analysis. Psychological Bulletin, 130(4), 531-552. https://doi.org/10.1037/0033-2909.130.4.531

Miyake, A., \& Friedman, N. P. (2012). The nature and organization of individual differences in executive functions: Four general conclusions. Current directions in psychological science, 21(1), 8-14. 
Nam, H., Jost, J., Meager, M., \& Van Bavel, J., (2021). Toward a neuropsychology of political orientation: Exploring ideology in patients with frontal and midbrain lesions. Philosophical Transactions of the Royal Society B: Biological Sciences.

Nock, M. K., Wedig, M. M., Holmberg, E. B., \& Hooley, J. M. (2008). The emotion reactivity scale: Development, evaluation, and relation to self-injurious thoughts and behaviors. Behavior Therapy, 39(2), 107-116. https://doi.org/10.1016/j.beth.2007.05.005

Rollwage, M., Dolan, R. J., \& Fleming, S. M. (2018). Metacognitive failure as a feature of those holding radical beliefs. Current Biology, 28(24), 4014-4021.

Rollwage, M., Zmigrod, L., de-Wit, L., Dolan, R. J., \& Fleming, S. M. (2019). What underlies political polarization? A manifesto for computational political psychology. Trends in cognitive sciences, 23(10), 820-822.

Silvers, J. A., McRae, K., Gabrieli, J. D. E., Gross, J. J., Remy, K. A., \& Ochsner, K. N. (2012). Age-related differences in emotional reactivity, regulation, and rejection sensitivity in adolescence. Emotion, 12(6), 1235-1247. https://doi.org/10.1037/a0028297

Sinclair, A. H., Stanley, M., \& Seli, P., Ph.D. (2019, December 21). Closed-Minded Cognition: Right-Wing Authoritarianism is Negatively Related to Belief Updating Following Prediction Error. https://doi.org/10.31234/osf.io/94a7v

Swann Jr, W. B., Gómez, A., Huici, C., Morales, J., \& Hixon, J. G. (2010). Identity fusion and self-sacrifice: arousal as a catalyst of pro-group fighting, dying, and helping behavior. Journal of personality and social psychology, 99(5), 824.

Uusberg, A., Taxer, J. L., Yih, J., Uusberg, H., \& Gross, J. J. (2019). Reappraising Reappraisal. Emotion Review, 11(4), 267-282. https://doi.org/10.1177/1754073919862617 
Valentino, N. A., Brader, T., Groenendyk, E. W., Gregorowicz, K., \& Hutchings, V. L. (2011). Election night's alright for fighting: The role of emotions in political participation. Journal of Politics, 73(1), 156-170. https://doi.org/10.1017/S0022381610000939

Van Hiel, A., Onraet, E., Crowson, H. M., \& Roets, A. (2016). The relationship between right-wing attitudes and cognitive style: A comparison of self-report and behavioural measures of rigidity and intolerance of ambiguity. European Journal of Personality, 30(6), $523-531$.

Van Zomeren, M., Postmes, T., \& Spears, R. (2008). Toward an integrative social identity model of collective action: a quantitative research synthesis of three socio-psychological perspectives. Psychological bulletin, 134(4), 504.

Zajonc, R. B. (1984). On the primacy of affect. American Psychologist, 39(2), 117-123.

Zmigrod, L. (2020). The role of cognitive rigidity in political ideologies: theory, evidence, and future directions. Current Opinion in Behavioral Sciences, 34, 34-39.

Zmigrod, L. (2020b, September 4). A Psychology of Ideology: Unpacking the Psychological Structure of Ideological Thinking. https://doi.org/10.31234/osf.io/ewy9t

Zmigrod, L., Eisenberg, I. W., Bissett, P., Robbins, T. W., \& Poldrack, R. (2020, April 14). A Data-Driven Analysis of the Cognitive and Perceptual Attributes of Ideological Attitudes. https://doi.org/10.31234/osf.io/dgaxr

Zmigrod, L., Rentfrow, P. J., \& Robbins, T. W. (2018). Cognitive underpinnings of nationalistic ideology in the context of Brexit. Proceedings of the National Academy of Sciences, 115(19), E4532-E4540.

Zmigrod, L., Rentfrow, P. J., \& Robbins, T. W. (2019). Cognitive inflexibility predicts extremist attitudes. Frontiers in psychology, 10, 989. 
Zmigrod, L., Rentfrow, P. J., \& Robbins, T. W. (2020). The partisan mind: Is extreme political partisanship related to cognitive inflexibility? Journal of Experimental Psychology: General, 149(3), 407-418.

Zmigrod, L., Rentfrow, P. J., Zmigrod, S., \& Robbins, T. W. (2019). Cognitive flexibility and religious disbelief. Psychological research, 83(8), 1749-1759.

Zmigrod, L., \& Tsakiris, M. (in press). A new decade of computational and neurocognitive approaches to the political brain: insights and directions. Philosophical Transactions of the Royal Society B: Biological Sciences.

Zmigrod, L., Zmigrod, S., Rentfrow, P. J., \& Robbins, T. W. (2019). The psychological roots of intellectual humility: the role of intelligence and cognitive flexibility. Personality and Individual Differences, 141, 200-208. 